\title{
Conditioning and retention of defensive burying as a function of Elavil and Thorazine injection
}

\author{
STEPHEN F. DAVIS, DAVID A. WHITESIDE, VIRGINIA A. DICKSON, \\ ROGER L. THOMAS, and DOUGLAS G. HECK \\ Emporia State University, Emporia, Kansas 66801
}

\begin{abstract}
Three groups $(n=10)$ of rat subjects received intraperitoneal injections of Thorazine, Elavil, and isotonic saline, respectively, prior to defensive burying testing. A defensive burying test session consisted of presenting each subject with an aversive stimulus (the discharge of a flashbulb) and recording the time each subject spent in burying behavior and the height of bedding material accumulated around the aversive stimulus during the ensuing $15 \mathrm{~min}$. A retention test was conducted $24 \mathrm{~h}$ later. During retention sessions, subjects were simply confined to the testing chamber for $15 \mathrm{~min}$. One half of the subjects in each group received retention testing under the same drug-injection condition used in the original conditioning session. The remaining subjects received retention tests under noninjection conditions. During the initial testing session, Thorazine-injected subjects spent significantly less time engaged in defensive burying and accumulated significantly less bedding material than did the salineinjected subjects. On the other hand, Elavil-injected subjects spent significantly more time burying and accumulated significantly more bedding material than did the saline-injected subjects. No significant differences, either in terms of time spent in burying or height of accumulated bedding material, were observed during retention testing.
\end{abstract}

Pinel and Treit (1978, 1979), Pinel, Treit, and Wilkie (1980), Terlecki, Pinel, and Treit (1979), and Wilkie, MacLennan, and Pinel (1979) have shown that rats afforded the opportunity may choose to defensively bury an aversive stimulus, rather than to flee, freeze, or attack. Further, Beninger, MacLennan, and Pinel (1980) have indicated that the conditioned defensive burying paradigm can be effectively used to unambiguously test the effects of pharmacological agents, such as the neuroleptic pimozide, on associative learning. As previous studies (e.g., Fibiger, Zis, \& Phillips, 1975; Ranje \& Ungerstedt, 1977) investigating such effects have tested drug-treated subjects, it has not always been possible to dissociate learning or associative deficits from motor disruption. With the conditioned defensive burying paradigm, subjects can be conditioned (e.g., shocked once by an electric prod) under the effect of the drug, removed from the apparatus, and then tested at a later time without the effect of the drug. Using this procedure, Beninger et al. (1980) found that subjects conditioned under the effect of pimozide and tested $24 \mathrm{~h}$ later without the drug buried the shock prod as much as did a group of rats initially conditioned without the effect of the drug. They concluded that neuroleptics, such as pimozide and haloperidol, do not appear to exert their effects through a modification of associative

This research was supported, in part, by a Research and Creativity grant from Emporia State University to the first author. processes, but rather through a disruption of motor performance. It is also worth noting that the pimozide subjects in this experiment were rendered hypoactive to such an extent that they had to be manually held on the shock prod during conditioning trials. Given these results, one wonders what effects would be produced by a catecholamine antagonist, such as chlorpromazine, that produces less severe motor deficits. Would similar results be obtained if the animal physically contacted the aversive stimulus under its own power? Also, would retention be influenced if subjects were allowed to engage in burying immediately after presentation of the aversive stimulus, but prior to retention testing? The Beninger et al. (1980) results would appear to prompt the conclusion that retention tests conducted under such conditions would not result in differences. Conversely, injection of a tricyclic compound that potentiates catecholamine action (e.g., amitriptyline $\mathrm{HCl}$, Elavil) prior to initial conditioning might be expected to increase the amount of defensive burying but not to result in superior retention.

To test these predictions, three groups of subjects received defensive burying testing under the effects of tricyclic (Elavil), chlorpromazine (Thorazine), and saline injections, respectively. Twenty-four hours later, all subjects were tested in the absence of the aversive stimulus for retention of conditioned defensive burying. One-half of the subjects within each group received retention tests under the same drug injection that was administered prior to initial conditioning. The remain- 
ing subjects received retention tests without the influence of the drug. Although the behavioral literature describing the effects of Elavil is rather limited, data reported by Cairncross, King, and Schofield (1975) is supportive of the first prediction. In this study, animals having bilateral olfactory bulb ablations showed an increase in avoidance learning performance when tested under the effects of amitriptyline injection. The lack of retention differences is predictable from the Beninger et al. (1980) data.

\section{METHOD}

\section{Subjects}

Thirty male albino rats purchased from the Holtzman Company, Madison, Wisconsin, served as subjects. The animals were individually caged with food and water available on a freefeeding basis. All subjects were approximately 120 days old at the beginning of the experiment.

\section{Apparatus}

A rectangular Plexiglas and glass enclosure $(25 \mathrm{~cm}$ wide, $45 \mathrm{~cm}$ long, $30 \mathrm{~cm}$ high) was used as the test chamber. The floor of the chamber consisted of $4.00 \mathrm{~cm}$ of San-I-Cel animal bedding material (Paxton Processing Company, Paxton, Illinois). An opaque plastic collar $(3.5 \mathrm{~cm}$ long $\times 3.00 \mathrm{~cm}$ in diameter was mounted in the center of an end (Plexiglas) wall of the testing chamber, $1 \mathrm{~cm}$ above the bedding material. The aversive stimulus, an M-3 flashbulb, was mounted inside the collar with contact leads exiting via a $2.00-\mathrm{cm}$ hole directly behind it

\section{Procedure}

As subjects were housed in standard wire-bottom cages, each subject received a 4-h habituation period to the San-I-Cel bedding material $48 \mathrm{~h}$ prior to defensive burying testing. Habituation sessions were conducted in rectangular enclosures similar, except for the absence of an aversive stimulus device, to that used for testing.

Following habituation, three groups, $E, T$, and $S(n=10)$, were randomly formed. One hour prior to initial defensive burying conditioning a $2-\mathrm{mg} / \mathrm{kg}$ intraperitoneal injection was administered to each subject. Subjects in Group E were injected with Elavil, subjects in Group $\mathrm{T}$ with Thorazine, and subjects in Group S with isotonic saline (.09\%).

The procedure for conducting a defensive burying conditioning trial consisted of placing the test subject in the center of the testing chamber facing away from the aversive stimulus. As soon as the subject came in close proximity to the plastic collar, the flashbulb was discharged. All subjects were confined to the testing chamber for $15 \mathrm{~min}$ following presentation of the aversive stimulus. Using Standard electric timers, two observers independently recorded the amount of time spent in defensive burying (moving bedding material toward or over the aversive stimulus) during this period. At the completion of each test session, the height of the additional bedding material accumulated around the aversive stimulus was measured at three points (left, right, and center), each located $3.00 \mathrm{~cm}$ from the stimulus object. If it did not coincide with one of these three points, the single highest point of accumulated bedding material was also recorded. As the floor of the testing chamber was smoothed to a uniform $(4.00-\mathrm{cm})$ height prior to the testing of each subject, it was possible to calculate the exact height of the additional bedding material that was accumulated in these locations during each session.

Each subject received a retention test $24 \mathrm{~h}$ after the original conditioning test. Prior to retention tests, each group was randomly divided into two equal subgroups $(n=5)$. One subgroup received retention tests under the same drug-injection condition that was in effect during the initial conditioning session. The other subgroup was tested without any type of injection. During retention tests, subjects were confined to the test chamber for $15 \mathrm{~min}$. The aversive stimulus was not presented during these sessions. However, an expended flashbulb was in place in the plastic collar.

\section{RESULTS}

\section{Original Conditioning}

As a high degree of agreement $(r=.91)$ existed between the two observers, regarding the amount of time each subject engaged in defensive burying, the two burying times for each subject were averaged before graphing and statistical analysis. A single score representing the height of the additional bedding material accumulated around the aversive stimulus was obtained by averaging the left, right, and center measurements taken after each test session. These average height scores were used for graphing and analysis purposes. Group means reflecting time spent in burying and height of additional bedding material accumulated around the aversive stimulus during the original conditioning session are shown in the left panels of Figures 1 and 2, respectively.

Analysis of variance of the time data yielded a significant groups effect $[F(2,27)=11.78, p<.01]$. Subsequent Newman-Keuls tests indicated that Group E spent significantly $(p<.01)$ more time burying than did Groups $\mathrm{S}$ and $\mathrm{T}$ and that Group $\mathrm{S}$ spent significantly $(p<.01)$ more time burying than did Group T.

Analysis of variance of the height of accumulated bedding material data also yielded a significant groups effect $[F(2,27)=8.19, p<.01]$. Newman-Keuls tests indicated that Groups $\mathrm{E}$ and $\mathrm{S}$ did not differ, but they accumulated significantly $(p<.01)$ more bedding material than did Group T. It should be noted that his analysis involved only those scores reflecting the bedding material accumulated around the aversive stimulus. A

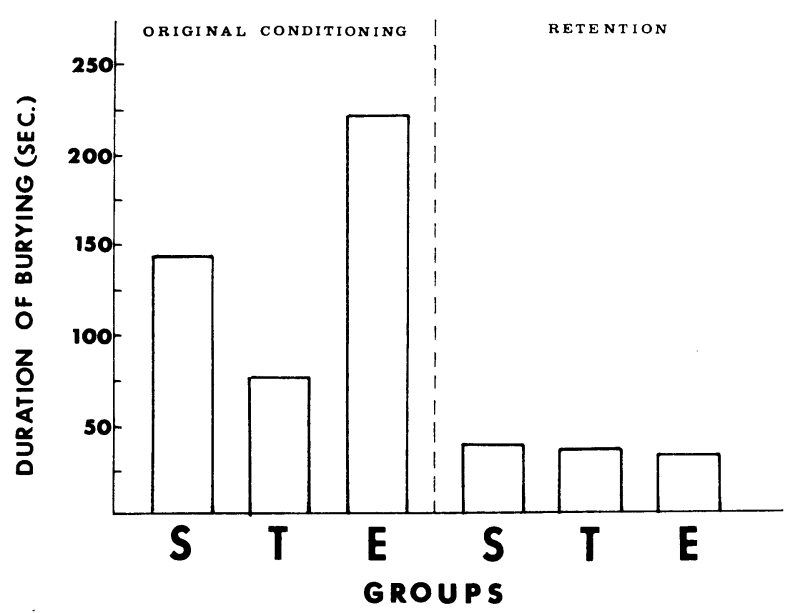

Figure 1. Mean time (in seconds) spent in burying behavior during original conditioning (left) and retention (right) sessions by saline (S), Thorazine (T), and Elavil (E) subjects. 


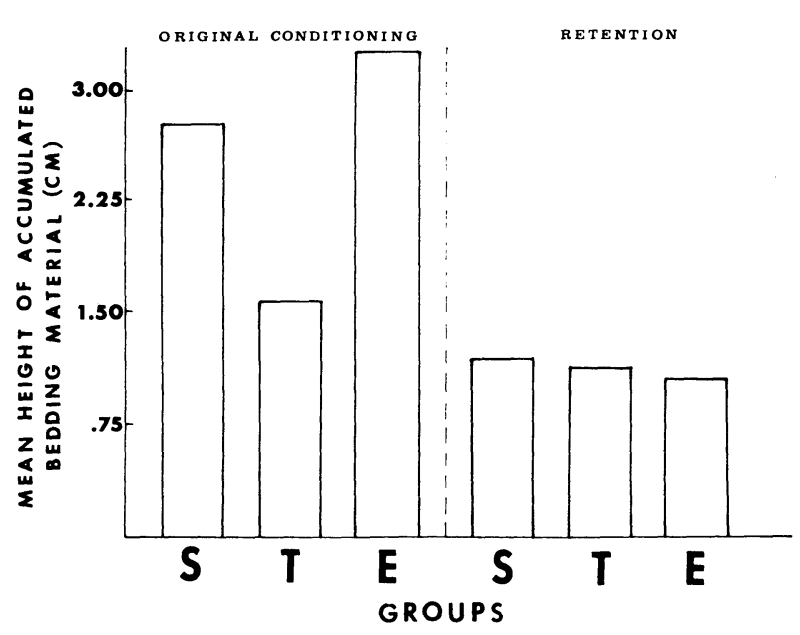

Figure 2. Mean height of bedding material accumulated around the aversive stimulus during original conditioning (left) and retention (right) sessions by saline (S), Thorazine (T), and Elavil (E) subjects.

somewhat different picture emerged when the scores representing the single highest point of accumulated bedding material were analyzed. (In the case of Groups $\mathrm{S}$ and $T$, these scores coincided with one of the three points measured around the aversive stimulus. They did not coincide in the case of Group E.) Analysis of variance of this data yielded a significant groups effect $[F(2,27)=36.42, p<.01]$. Newman-Keuls tests indicated that Group E accumulated significantly $(\mathrm{p}<.01)$ more bedding material than did Groups $\mathrm{S}$ and $\mathrm{T}$ and that Group $S$ accumulated significantly $(p<.01)$ more bedding material than did Group T.

\section{Retention}

Prior to overall analysis, comparisons ( $t$ tests) of the two subgroups (drug vs. no drug) were made within the $\mathrm{E}, \mathrm{S}$, and $\mathrm{T}$ conditions for both the burying time and the height of bedding material measures. As these comparisons failed to approach significance [the largest obtained value of $t(8)=.54$ ], the scores from the drug and nodrug subgroups were pooled within Groups E, S, and T for graphing and analysis purposes. Group means reflecting time spent in burying and height of bedding material accumulated around the aversive stimulus during retention testing are shown in the right panels of Figures 1 and 2 , respectively.

Analysis of variance of the time data failed to yield a significant groups effect $[F(2,27)=.16, p>.50]$. Likewise, analysis of the height of bedding material data failed to yield a significant groups effect $[\mathrm{F}(2,27)=$ $.06, \mathrm{p}>.50]$.

\section{DISCUSSION}

The significant depression in the duration of defensive burying during the original conditioning session on the part of the Thorazine-injected subjects and the increase in such behavior shown by the Elavil-injected subjects establishes that performance of this behavior is sensitive to these adrenergic drug states. A consideration of the height of accumulated burying material measure prompts essentially the same conclusion.

The lack of between-group retention differences is certainly in agreement with the data reported by Beninger et al. (1980) and suggest that the drug-induced differences observed during the original conditioning session reflect performance, as opposed to associative, effects. The lack of retention differences between the drug-injection and noninjection subgroups within Groups T, S, and E would appear to rule out a statedependent learning interpretation.

In addition to the similarities between the present data and those reported by Beninger et al. (1980), differences, apparently due to variations in subjects and/or testing procedures, appear worthy of consideration. Even though test sessions were also conducted by Beninger et al. $24 \mathrm{~h}$ following conditioning, their animals, when conditioned under the influence of pimozide and tested under noninjection conditions, spent more time engaged in defensive burying and accumulated more bedding material around the aversive stimulus than our subjects did during retention testing. For example, the Beninger et al. subjects averaged over $200 \mathrm{sec}$ in defensive burying and accumulated over $4 \mathrm{~cm}$ of bedding material around the aversive stimulus. These figures are in sharp contrast to the retention averages of $34.16 \mathrm{sec}$ for burying time and $1.19 \mathrm{~cm}$ for accumulated bedding material. This difference may be attributed to the fact that the Beninger et al. subjects were removed from the test chamber $10 \mathrm{sec}$ after being shocked. Thus, they were not allowed to engage in burying until the test session $24 \mathrm{~h}$ later. In the present study, subjects were allowed to engage in burying during the 15 -min period immediately following presentation of the aversive stimulus and the 15 -min retention session $24 \mathrm{~h}$ later. It may be that allowing subjects to engage in defensive burying immediately following presentation of the aversive stimulus has the effect of decreasing the intensity and/or duration of this behavior in subsequent sessions.

Such differences might also be attributed to the use of different aversive stimuli. Whereas Beninger et al. (1980) employed electric shock, a flashbulb was used in the present study. Davis and Rossheim (1980) have reported data relevant to this possibility. Even so, it does not seem reasonable to attribute the full extent of such differences to this factor.

A third possible influence concerns the use of hooded rats by Beninger et al. (1980) and the use of albino rats in the present study. Tarte and Oberdieck (Note 1) have recently reported that hooded rats spend significantly more time engaged in burying than do albinos. Hence, this subject difference may have depressed retention performance to some degree in the present study.

Such differences certainly suggest viable parameters that might well be incorporated into further investigations of this phenomenon. On the other hand, such considerations do not detract from the main findings of this study, namely, that performance of defensive burying is influenced by injections of catecholamine antagonists (e.g., Thorazine) and agonists (e.g., Elavil) and that retention of this response is not influenced by the creation of such drug states at the time of original conditioning.

\section{REFERENCE NOTE}

1. Tarte, R., \& Oberdieck, F. Conditioned defensive burying in rats as a function of preexposure and strain. Paper presented at the annual meeting of the Psychonomic Society, St. Louis, Missouri, 1980. 


\section{REFERENCES}

Beninger, R. J., Maclennan, A. J., \& Pinel, J. P. J. The use of conditioned defensive burying to test the effects of pimozide on associative learning. Pharmacology, Biochemistry and Behavior, 1980, 12, 445-448.

Cairncross, K. D., King, M. G., \& Schofield, S. P. Effect of Elavil on avoidance learning in rats following olfactory bulb ablation. Pharmacology, Biochemistry and Behavior, 1975, 3, 1063-1067.

Davis, S. F., \& Rosshe im, S. A. Defensive burying as a function of insulin-induced hypoglycemia and type of aversive stimulation. Bulletin of the Psychonomic Society, 1980, 6, 229-231.

Fibiger, H. C., Zis, A. P., \& Phillips, A. G. Haloperidolinduced disruption of conditioned avoidance responding: Attenuation by prior training or by anticholinergic drugs. European Journal of Pharmacology, 1975, 30, 309-314.

Pinel, J. P. J., \& Treit, D. Burying as a defensive response in rats. Journal of Comparative and Physiological Psychology, $1978,92,708-712$.
Pinel, J. P. J., \& Treit, D. Conditioned defensive burying in rats: Availability of burying materials. Animal Learning \& Behavior, 1979, 7, 392-396.

Pinel, J. P. J., Treit, D., \& Wilkie, D. M. Stimulus control over defensive burying in the rat. Learning and Motivation, 1980, 11, 150-163.

RANJe, L., \& Ungerstedt, U. Discriminative and motor performance in rats after interference with dopamine neurotransmission with spiroperidol. European Journal of Pharmacology, 1977, 43, 39-46.

Terlecki, L. J., Pinel, J. P. J., \& Treit, D. Conditioned and unconditioned defensive burying in the rat. Learning and Motivation, 1979, 10, 337-350.

Wilkie, D. M., MacLenna, A. J., \& Pinel, J. P. J. Rat defensive burying: Burying noxious food. Journal of the Experimental Analysis of Behavior, 1979, 31, 299-306.

(Received for publication February 2, 1981.) 